\title{
Designações versus conceções da infância portuguesa nos dicionários e discursos (séc. XIX e parte do XX)
}

\author{
Designations versus conceptions of portuguese childhood in dictionaries and speeches (19th \\ century and part 20th)
}

\section{Designaciones versus concepciones de la infancia portuguesa en los diccionarios y discursos (Siglo XIX y parte del XX)}

\author{
Ernesto Candeias Martins - Instituto Politécnico de Castelo Branco - Escola Superior de Educação | \\ Departamento de Ciências Sociais e Humanas | Castelo Branco | Portugal. E-mail: ernesto@ipcb.pt | \\ (i) ORCID
}

Resumo: Trata-se de um estudo histórico-descritivo, de teor hermenêutico, construído na base da literatura e escritos da época sobre a conceção social da criança e da sua infância, com recurso a designações, nomenclaturas ou adjetivações nos dicionários e discursos científicos (médico-higienistas, jurídico-legais, pedagógicos) e político-ideológicos, no período do séc. XIX até 1930. Em especial, abordaremos a 'Outra' infância, a qual a classificamos como infância diferenciada da dita normal por estar à margem da normalização e escolarização imposta pela sociedade. Norteamo-nos por uma tríade de objetivos, que correspondem aos pontos de abordagem: compreender a designação referencial etimológica dos termos criança-infância (dicionários) articulada com a linguagem discursiva científica da época; explicar as diversas conceções e termos afins que integra a 'Outra Infância' por nós utilizada; conhecer o significado das categorias de menor estabelecidas na Lei de Proteção à Infância, de 1911 em sintonia com as medidas tutelares de proteção.

Palavras-Chave: Conceções da infância. Designações outra infância. História social.

Abstract: This is a historical-descriptive study, of hermeneutic content, constructed on the basis of literature and writings of the time on the social conception of the child and his childhood, using designations, nomenclatures or adjectives in dictionaries and scientific discourses (medical-hygienists, legal-legal, pedagogical) and political-ideological, in the period of the century. 19th century to the 1930. In particular, we will approach the 'Other' childhood, which we classify as a childhood differentiated from the so-called normal because it is on the margins of normalization and schooling imposed by society. We are guided by a triad of objectives, which correspond to the points of approach: to understand the etymological referential designation of the terms child - childhood (dictionaries) articulated with the scientific discursive language of the time; explain the various designs and related terms that includes the 'Other Childhood' used by us; to know the meaning of the categories of minors established in the Child Protection Act of 1911 in line with the protective measures of protection.

Keywords: Conceptions of childhood. Designations another childhood. Social history. 
MARTINS, Ernesto Candeias. Designações versus conceções da infância portuguesa nos dicionários e discursos (séc. XIX e parte do XX).

Resumen: Se trata de un estudio histórico-descriptivo, de contenido hermenéutico, construido sobre la base de la literatura y de los escritos de la época sobre la concepción social del niño y su infancia, con recurso a las designaciones, nomenclaturas o adjetivos de los diccionarios y discursos científicos (médico-higienistas, jurídico-legal, pedagógico) y políticoideológicos, en el período del Siglo XIX a 1930. En particular, nos acercaremos a la 'Otra Infancia', la cual clasificamos como una infancia diferenciada de la llamada normalidad, que estaba en los márgenes de normalización y escolarización impuestos por la sociedad. Nos guiamos por una tríada de objetivos, que corresponden a los puntos de enfoque: entender la designación referencial etimológica de los términos niño - infancia (diccionarios) articulado con el lenguaje discursivo científico de la época; explicar los diversos diseños y términos relacionados que incluyen la 'Otra Infancia' utilizada por nosotros; conocer el significado de las categorías de menores establecidas en la Ley de Protección de la Infancia de 1911 de conformidad con las medidas de protección.

Palabras-clave: Concepciones de la infancia. Designaciones de otra infancia. Historia social. 


\section{Introdução à temática}

A criança e a sua infância e/ou os menores, sendo conceitos distintos nas suas conceções e representações, segundo o discurso que utilizemos na sua significação referencial, foram a causa de debates e publicações a partir da Modernidade, considerado um problema social que havia que proteger, assistir e acolher. Utilizamos o termo representação social como conjunto de fenómenos que integra um conceito com a respetiva teoria(s) de explicação, que identifica um vasto número de estudos, no âmbito sociopedagógico e psicológico. O historiador social, no contexto cultural, deve analisar as fontes, que ancoram o estudo de aproximação à conceção científica e política da infância, da sua representação e construção social. Em Portugal a problemática da infância tem produzido muitas publicações, a maior parte elaboradas por historiadores, na base do enfoque e objeto desse estudo, em especial, sobre expostos, criança pobre, abandonada, desvalida, em risco, delinquente ou criminosa. Essas análises objetivam os sentidos da infância, as suas conceções, nos três últimos centúrios (BORRAS LLOP, 1996).

A nossa argumentação histórico-descritiva, de teor hermenêutico, constrói-se teórica e metodologicamente na literatura da época e escritos posteriores sobre a conceção social da criança e da sua infância, recorrendo às designações e/ou adjetivações expressas nos dicionários e, ainda, aos discursos científicos (médico-higienistas, jurídico-legais e pedagógicos) e políticos, no período do séc. XIX até ao início do Estado Novo (1930). Deste propósito, advém uma tríade de objetivos, que correspondem aos nossos pontos de abordagem: compreender a designação referencial etimológica dos termos 'criança-infância'(dicionários) articulando-as com a linguagem discursiva científica da época; explicar as diversas conceções e termos afins que integram a 'Outra Infância'; compreender o significado das categorias de menor estabelecidas na LPI - Lei de Proteção à Infância, de 27 de maio de 1911 (PORTUGAL, 1911), em sintonia com medidas tutelares de proteção e de prevenção.

Em todo este arco histórico teremos, em conta o surgimento do problema social e a configuração político-ideológica e científica dessa 'Outra' infância, que era diferenciada da dita normal por estar à margem da normalização e escolarização imposta pela sociedade, provocada por situações sociais/familiares e condições de conflito e, por isso, afastavam-se do percurso normal de socialização. Estas infâncias necessitavam de intervenções de proteção, assistência e educação/correção em estabelecimentos específicos. Será, pois fundamental entender as 
aceções derivadas e construídas dessa 'Outra Infância', principalmente as referidas à criança pobre, mendiga, abandonada, vadia, desvalida, marginalizada, delinquente ou infratora. Ou seja, todas as conceções integradas no chapéu da 'Outra Infância', que refletiam as suas situações de desviação social, com necessidade de um política social efetiva. É óbvio que o conteúdo dessas conceções e enfoques conceptuais da 'Outra Infância' foi construído, no tempo e na memória histórica, com necessidade duma interpretação historiográfica.

O fenómeno da 'Outra Infância' remete-nos conceptualmente para um grupo de crianças com a sua infância que, devido a situações (familiares, sociais, ambientais, culturais) e condições de conflito, eram obrigados a sair do lar e serem vítimas de influências indevidas na rua ou meio social. Ora este estado daquelas infâncias implicou do Estado um controlo policial e de assistência/educação, muitas iniciativas de índole filantrópica e benemérita, intervindo sobre a vadiagem e mendicidade, o abandono moral e ausência física dos pais, dos atos de delinquência dessas crianças. Essa 'Outra Infância' foi, historicamente, vista como recetáculo de assistência social, do patronato e da intervenção do Estado, sendo concebida como uma estratégia de construção de uma ordem política imposta. O positivismo foi o motor do pensamento do séc. XIX e dos postulados do liberalismo, tendo encarado a criança, a infância pobre, abandonada, desvalida e delinquente como uma questão social, nos diversos discursos. Por detrás desses discursos havia uma realidade construída de miséria, pobreza, abusos e imoralidades, doenças sociais no meio familiar e envolvente e, por isso, as crianças viviam esse pauperismo e instabilidade da família. A partir da LPI (PORTUGAL, 1911), passou a haver uma maior insistência na assistência social e infantojuvenil, na proteção ao menor, nos apoios às famílias e à (re) educação dessa 'Outra Infância', regularizada por diplomas posteriores (PORTUGAL, 1925).

\section{Argumento: a criança e a infância nos dicionários e discursos da época}

A criança e a sua infância, no arco histórico do estudo, exige epistemologicamente uma clarificação conceptual e terminológica, quer na analogia e/ou sinónimos e pelos significados e/ou designações, no tempo histórico e regimes políticos (Monarquia Constitucional e $1^{\mathrm{a}}$ República), quer ainda pela influência dos discursos de várias ciências.

Desde a Modernidade até à Contemporaneidade a criança apresenta várias conceções, por exemplo, H. Hendrick (1990, p. 41-43), indica as seguintes designações: criança romântica (Séc. 
XVII); criança trabalhadora que, precocemente, era vítima das profundas alterações sociais, familiares e económicas como resultado da revolução industrial e, por isso, trabalhava na agricultura, fábricas, minas, serviços (vendedores ambulantes, marçanos), etc., contribuindo para a economia familiar e/ou caprichos; criança delinquente que, pelos seus comportamentos antissociais, infratores e indigentes, era uma ameaça à ordem pública, mas teve a sensibilidade dos filantropos para os seus problemas e condições de vida, originando respostas sociais; criançaaluno surgida, a partir do séc. XVIII à criação da escola pública, mas oriunda da conceção 'criança delinquente', em que só uma boa e moralizadora educação e uma ação socializadora da escola era o ideal para que ela fosse educada (educabilidade); criança médico-psicológica proveniente de finais Séc. XVII e legitimada em oitocentos, provinha dos discursos e saberes médicos, biológicos, higienistas, pedagogos, psicologia infantil e psicanálise, de tal modo, que mereceu uma análise científica clarificadora dos seus comportamentos, qualidades, ritmo de desenvolvimento; criança bem-estar, a partir do Séc. XIX, ao ser reconhecida social e legalmente a sua natureza infantil, através de uma conceção materializada pelo aparecimento de novos serviços de apoio, no âmbito da prevenção social, saúde e educação; criança de jurisdição psicológica com necessidade de couselling, acompanhamento e orientação psicológica e educacional; a criança de família que inclui a criança pública, as crianças colocadas em famílias de atendimento, acolhimento e adoção.

A variabilidade histórica do conceito infância parece ser comum a todas as sociedades ocidentais, acompanhando a evolução do pensamento político-ideológico, económico, científico, cultural e educativo europeu e os processos sociais experienciados pelas sucessivas gerações. É a partir de meados do século passado que assistimos a um processo de reconstrução das conceções de infância, herdadas de oitocentos. Neste percurso histórico, segundo Donzelot (1977, p. 29), a criança e a sua "infância passou a ser legitimada pelos discursos" científicos, pelo apoio material da filantropia e beneficência, intervindo o Estado (tutor) no processo de socialização infanto juvenil, através da moralização, normalização e contrato-tutela (direito tutelar).

Vejamos, quais os significados terminológicos e referenciais, indicados nos dicionários e respetivos discursos de oitocentos e parte de novecentos sobre a criança e a infância, de modo, a termos uma conceção ou representação ajustada às ideias da época: 
a) Criança. É um facto, que após a influência do naturalismo ou ambientalismo pedagógico de J. J. Rousseau, a criança passou a ser vista em oitocentos como uma fase de vida que lhe era específica, preenchendo a sua definição os discursos médicos, higienistas e pedagógicos, o que implicava a dependência do ato de ser criada e provida de sustento Este conceito evoluiu, de tal forma, que F. Constâncio (1844, p. 330) defini-a como "filho novo, menino ou menina, cria, pequenina, mui tenra idade”. Posteriormente, no início de novecentos, para além da mudança de ortografia de 'creança' (para criança), o Dicionário da Língua Portuguesa Etimológico e Ortográfico (1918, p. 278) referia-se a ela como "indivíduos dos dois sexos no período da infância", mas é mais explicito e amplo o seu significado dado pelo Dicionário de F. J. Caldas Aulete (1925, p. 597) ao designá-la por “indivíduo da espécie humana que está no período da infância. Creança de peito e que ainda mamma. Ser creança, entreter-se com coisas pueris, ser leviano, não tratar os negócios com seriedade". De facto, a criança começou a ser vista numa fase de vida do ser humano que lhe era específica e que se designava por infância, para além de indicar a dependência do ato de ser criado por alguém que lhe provê o seu sustento (BASTOS, 1913). Mais tarde, Torrinha (1931, p. 408) faz um reducionismo ao conceito de criança considerando-a como o "ser humano que se começa a criar; menino ou menina", consolidando, assim, a definição de "primeiro período da vida humana associado às crianças" (p. 770). Estas ao passarem a ser reconhecidas como membros de um grupo social distinto e baseado na idade, a sua infância era a etapa do ciclo vital do seu desenvolvimento. Daí que a compreensão das conceções de infância passou a terem conta o período temporal (extensão), a sua natureza (qualidades, capacidades), nas suas dimensões (várias perspetivas e atributos) e no seu significado. Assim, qualquer conceção singular de criança e/ou de infância funcionava mais como construção social do que realidade. Ora essa representação social dependia em muito da família e dos contextos socioculturais, económicos, éticos, político-ideológicos, pedagógicos, judiciais, médicos e assistenciais.

Historicamente, segundo Heywood (2004), as crianças consideravam-se uns simples adultos imperfeitos, que estavam a eles subordinados e, por isso, consideradas como anormais e/ou deficientes. De facto, a infância, como etapa da vida, surgida na Modernidade, implicou uma nova realidade social, no seio da família e da sociedade, promovendo igualmente instituições assistenciais e educativas para o seu apoio, como foram os asilos e recolhimentos, para além, da escola (escolarização). 
Os discursos médicos e psicopedagógicos deram visibilidade à natureza da criança e da sua infância, de tal modo, que se gerou uma ideologia de defesa da mãe e da sua maternidade (cuidados e serviços), ou seja, divulgou-se a ideia de que a criança deveria ter uma boa 'família' ou boas mães e, isto, fez surgir processos de socialização para que se aceitassem essa condição e dignificassem a sua função maternal e familiar, assim como as competências domésticas e educativas. Na base daquelas ciências médicas, as ações de assistência e educação (popular) pretendia gerar hábitos, costumes e valores nas classes sociais e nas famílias mais vulneráveis ou desprotegidas. Era uma sociedade que tanto valorizava a família, como centro de desenvolvimento do modelo económico capitalista (liberal), que conhecia as desigualdades sociais e a situação insustentável das condições de vida de muitas famílias das classes trabalhadoras, como ainda propunha intervenções (profilaxia social, higiene social, assistência materno-infantil, sanitária) e criação de instituições para exercer a sua ação paralela e até substituta de educação da criança. A pretensão era submeter a infância aos padrões sociais, morais, cívicos e sanitários considerados necessários para o desenvolvimento da sociedade.

b) Infância. Nos diversos dicionários, o termo infância referia-se: ao período que vai do nascimento ao início da adolescência; à meninice e puerícia; ao conjunto de crianças; ao começo, nascimento de algo; à falta de maturidade; à ingenuidade, inocência (HOUAISS; VILLAR, 2002). O Dicionário de José da Fonseca (1874, p. 604) remetia a infância para "princípio; idade do menino até sete anos", considerado como atributo do ser masculino e com essa idade. Em novecentos o termo, no dicionário de Caldas Aulete (1925), passou a ser o estado ou idade de vida da criança, delimitada pela ausência da fala ou pela fala imperfeita (diríamos hoje proto linguagem), até aos 7 anos, referindo-se também aquela fonte à infância desvalida nos asilos. Ora a nova realidade social, no início do séc. XX, fez uma precisão do termo como etapa de vida, em que a criança apresenta falta de discernimento moral nos seus atos, que se estendia até à puerícia (10 ou 12 anos), ou seja, passou haver nesta etapa uns atributos e caraterísticas específicas até à adolescência. No dicionário de Torrinha (1931) essa definição consolida-se considerando a infância ao primeiro período da vida humana associado às crianças. A infância considerou-se a etapa do ciclo vital do desenvolvimento da criança, sendo que a compreensão das suas conceções se baseavam no período temporal, na sua natureza (qualidades, capacidades) e no seu significado. 
Por isso, essas conceções variavam segundo as suas fronteiras (começo e fim da infância), das suas dimensões (distintas perspetivas e atributos) e as divisões em $1^{\mathrm{a}}, 2^{\mathrm{a}}$ e $3^{\mathrm{a}}$ infância e adolescência. Ou seja, qualquer conceção sobre a infância estava em função das fronteiras referidas anteriormente e, ainda, entre a fronteira da 'normalidade' (escolarização, normalização) e da 'anormalidade' (fora das normas sociais). De facto, a conceção singular de criança ou de infância, sendo o período inicial da vida humana, funcionava mais como construção social (e cultural), no tempo histórico das representações, do que realidade. Portanto, o termo infância reunia os sentidos e significados que as sociedades atribuíram, e atribuem, a esse período de vida.

Na verdade, D. Archard (1993) considera que as sociedades adotaram um conceito de infância e uma ideia desta etapa do ser humano, mesmo existindo várias conceções, já que aquele termo exige que as crianças se diferenciem dos adultos, segundo um leque de atributos. Por isso, a conceção de infância seria a especificação dessas caraterísticas próprias da criança, sabendo que cada sociedade tem, segundo a cultura e o momento histórico, um conceito de infância, ou seja, uma consciência dessas particularidades. Se Stearns (2006) justifica o 'modelo de infância moderna', apoiando-se nas modificações ocorridas no Ocidente e na América (desde Séc. XVII) e Cunningham (1998), com abordagens historiográficas (construção cultural) de ideias sobre a maneira como a infância variou nas diferentes culturas e com valores distintos, já Colin Heywood (2004), através de uma análise aos estudos históricos da infância, procura as distintas concepções, em diferentes períodos históricos, para assim, com as fontes e condições culturais predominantes nessas épocas, explicar as conceções conflituantes ou ambivalentes relativamente à infância, em cada sociedade. Daí que a ênfase historiográfica permite-nos desvelar a natureza específica da infância, mesmo que implique interpretações diferentes da consideração da infância como uma construção social, já que ela variou e varia nas diversas sociedades.

\section{Argumento: nomenclaturas e adjetivações na conceção da 'outra infância'}

Explicada a designação de 'Outra infância', a qual não possuía um domicílio fixo, nem meios de subsistência, nem atenção educativa, assistencial e afetiva, andando ao 'Deus dará' (vadiagem) pelas ruas e vielas das cidades e circulando ilegalmente nos transportes públicos, etc. A forma irregular e errante dessa infância leva-nos a classificá-la por criança 'da rua' e 'na rua'. O sujeito e o espaço são idênticos nos dois tipos, mas a diferença está na relação que mantém ou não com a família/tutores. Na categoria 'criança da rua' incluímos as infratoras (pré- 
delinquente) e em perigo moral ou em risco, que não mantinha nenhum ou escasso contacto com a família/tutores, sendo a rua o seu meio de subsistência e sobrevivência, através do roubo e furtos com ou sem agressões (MARTINS, 2006). Tratava-se de crianças que trocaram a escolarização pela 'escola da rua', com manifestação de comportamentos desviantes, antissociais, delitivos ou de delinquência com atos ilegais ou de criminalidade. No seu processo de socialização mostravam instabilidade nas relações, agressividades, com repercussão na identidade do 'eu', moldando-se ao espaço privado da 'rua', onde realizava a sua atividade delitiva. $\mathrm{Na}$ 'criança na rua' incluímos aquelas que mantinham contactos assíduos com família/tutores, mas estes, devido a determinadas situações laborais (emprego esporádico, desemprego, número elevado horas de trabalho) ou impedimentos (jurídico-penais e morais), não lhes davam o sustento nem educação, como ainda as exploravam pelo trabalho (familiar), ou nos empregos, ou pela mendicidade e crimes. Daí que estas crianças/jovens refugiavam-se na rua durante o dia para realizar as suas atividades e sobreviverem no imediatismo de satisfação das necessidades básicas, sem terem uma infância normal.

$\mathrm{Na}$ verdade, as infâncias, à margem da sociedade da sua época, foram-lhes atribuídas definições nos dicionários que nos ilustram (novas) realidades acerca da sua pobreza, mendicidade, vadiagem, marginalidade, abandono e desvio social que, em casos extremos, levam-nas a delinquir ou a infringir delitos, punidos pelos códigos penais no Séc. XIX (1850, 1878, 1890) e, posteriormente pela LPI (PORTUGAL, 1911). Essas situações sociais e/ou condições de conflito repercutiam-se nos próprios conceitos de infância e de criança, alterando o enfoque social em relação essa 'Outra Infância'. Nesta adoção do termo 'Outra Infância' integrámos nele una panóplia de conceitos de infância, a saber: pobre, mendiga ou ociosa, abandonada, desprotegida/desfavorecida, desamparada, desvalida, vagabunda ou vadia (galdéria), errante (sem destino) e, ainda, infratora (=transgressora) ou delinquente. Para compreendermos as suas nomenclaturas e adjetivações recorremos aos seus significados nos dicionários, no período histórico do nosso estudo, identificando as suas conceções e/ou conceptualizações, as quais se associavam aos discursos de algumas ciências (médicas, juristas, pedagógicas). Vejamos essas aceções etimológicas de algumas categorias que integram a 'Outra Infância':

a) Infância pobre (ociosa, mendiga). Portugal ao longo do Séc. XIX e quase todo séc. XX teve períodos com índices elevados de pobreza e miséria material e moral nas famílias (populares, 
pobres, desfavorecidas, excluídas), grande concentração urbana em Lisboa e Porto, falta de condições habitacionais ou sem casa (viviam choças, bairros de lata), elevado analfabetismo (infantil), desemprego (a procura superava a oferta), pessoas esmolando e mendigando, vagabundagem etc. Ora bem, sendo a criança uma construção social e cultural, oriunda de práticas e representações, num tempo e espaço histórico, é necessário compreender esses sentidos de pobreza, pois, só assim se poderia tecer as relações da criança pobre com ajuda e ação da filantropia (LOPES, 2010).

Etimologicamente no Dicionário da Língua Portuguesa (2005, p. 1180) pobre e/ou pobreza "associava-se a terrenos agrícolas que não produziam ou eram inférteis". Com os tempos a palavra pobre passou a ter vários significados, uns relacionados com alimentação, moradia, cuidados de saúde, incapacidades, falta de educação e de acesso à cultura, e outros significados relacionando-o com carências de bens essenciais, perpassando a ideia de miséria na condição humana. Outro elemento associado á pobreza era o pauperismo, que era a forma mais dramática da pobreza e que supunha a sobrevivência de alguns e a dependência auxílios. Na verdade, o pobre no séc. XIX definia-se como "falto do necessário para viver, pouco fértil, mendigo" (FONSECA, 1874, p. 604) ou, então, no caso do Dicionário de Caldas Aulete (1925, p. 278):

[...] Falto ou privado do necessário; que vive com poucas posses. Diz-se d'aquelle cujas posses são inferiores à sua posição ou condição social. Mal dotado, pouco favorecido. Infeliz, desprotegido; digno de lastima ou de compaixão. Que inspira dó. Particularmente, pessoa que vive de esmolas, que mendiga.

Torrinha (1931, p. 104) considera pobre como "pessoa que não tem o necessário à vida; infeliz; pedinte", que vivia em mendicidade e da caridade humana, muitas vezes esmolando. Assim, em novecentos, o pobre implicava um ser "desprotegido, digno de compaixão indigência, miséria, penúria” (MICHAELIS, 2002, p. 610). Para E. C. Martins (2015, p. 159) "pobre é alguém com falta de recursos, encontrando-se excluído dos hábitos, das normas sociais e dos costumes decorrentes na sociedade em que vive". Se unirmos o estado de pobreza ao de exclusão social, que é uma noção definida e aprofundada por Bruto da Costa (1998, p. 13): “os seus recursos (dos pobres) ficam tão seriamente abaixo dos controlados pelo indivíduo ou família, que eles ficam de facto excluídos dos padrões de vida, costume e atividades". Deste modo, a exclusão social conotava-se com a pobreza, o desemprego, a mendicidade (os sem abrigo), as pessoas mal deformadas e com baixa autoestima, em precariedade e vulnerabilidade 
social (PINTO, 1999). Todas estas privações (múltiplas) nas famílias mais desfavorecidas, em grupos e coletivos vulneráveis tinham consequências nas crianças e/ou jovens, na sua educação (sem escolarização), na saúde e assistência médico-sanitária, nas condições de habitabilidade, no défice ou falta de alimentação (desnutrição), no vestuário (poucas vestes), no transporte, etc. Assim, a consequência da pobreza familiar poderia ser o abandono, o desamparo e a marginalidade nas crianças/jovens, o que provocou, historicamente (desde a criação das misericórdias), a caridade social religiosa e filantrópica, com o aparecimento de instituições de acolhimento e proteção, a profilaxia social, a assistência e educação, os asilos, etc., uma vez que se devia prevenir situações de 'em perigo moral', errância, desvio social, delinquência e criminalidade, as quais punham em causa a segurança e paz social. A partir da LPI (PORTUGAL, 1911) atenuou-se, com medidas jurídico-sociais e tutelares, muitas dessas situações das crianças/jovens.

b) Infância abandonada e desamparada. $\mathrm{O}$ abandonado (adjetivo: desamparado) significa uma espécie de termo geral, com referência ao desamparado, onde se incluía as "crianças sem pais (órfão) ou de pais desconhecidos, ilegítimos ou sem paradeiro", tal como é indicado no Dicionário de Caldas Aulete (1881, p. 10). Mesmo que a criança tivesse família, esta encontravase em situação desestruturada, em precariedade e/ou pobreza, com doenças e vícios (sífilis, alcoolismo, tuberculose, doença mentais) ou detida como criminosos e, por isso, impeditiva da tutela dos seus filhos, os quais caiam no desamparo e abandono (LOPES, 2010). Para estas crianças a assistência e a educação pelo trabalho era a saída possível para se regenerarem moralmente e serem cidadãos úteis.

Nos dicionários do séc. XIX, de Francisco Solano Constâncio (1844, p. 330-331) e de Agostinho Falcão (1858, p. 4) abandonado significava "desamparado" (moral e materialmente), “aquele que era deixado ao abandono". Mais tarde, José da Fonseca no seu Dicionário (1874, p. 3) associa a essa designação a de um "ser solitário", no sentido de dissoluto, perdido, entregue à ociosidade, à mendicidade e vagabundagem. Já em novecentos o Dicionário de Caldas Aulete (1881, p. 5) relaciona abandono e/ou abandonado com os expostos, ou seja, aquelas crianças cujos pais/família deixam de ter cuidados com essa criança, por falta de meios e condições, ou por ser, órfã, filho/a ilegítimo/a ou de pai desconhecido. O termo abandonado não aparece no Dicionário de Torrinha (1931). 
De facto, a infância abandonada nos discursos vigentes da época poderia ser:

i.Infância abandonada materialmente, que incluía: órfãos; expostos nas Rodas (Portaria legal de 9/10/1839 esteve em vigor até finais de oitocentos, passando a incluir os expostos maiores de 7 anos); crianças maiores de 7 anos em situação de desamparo; pobres ou miseráveis, sem meios de subsistência, em situação de indigência, ociosidade e vagabundagem, dedicando-se a mendigar e esmolar, motivos de detenção e encerramento institucional .

ii.Infância abandonada moralmente, que integrava: crianças em estado de vagância, vagabundagem e vadiagem, normalmente dedicada à mendicidade habitual; crianças que por motivo de maus-tratos, violência familiar (das madrastas e padrastos) e outros atos de crueldade, abuso de autoridade, negligência, sendo explorados pelos pais, tutores ou lideres de bandos, tornando-se vítimas de maus-tratos físicos, castigos, explorações laborais em situações inumanas e imorais (p.e. descarga de carvão nos Cais do Sodré em Lisboa, nas fábricas), de prostituição, criminalidade, etc.; crianças/jovens que tendo família ou tutores, dedicavam-se extorquir, a infringir roubos/furtos, a delinquir ou executando delitos/crimes punidos pelos Códigos Penais e, depois pelo direito tutelar de menores.

Evidentemente, que as situações de abandono e desamparo deviam-se a razões e/ou condições familiares de ordem económica (pobreza, miséria), de ilegalidade matrimonial ou desorganização familiar, orfandade, imoralidades e maus-tratos/abusos, ao estado social dos pais (desemprego, vícios, doenças, mendicidade e ociosidade) (RELVAS, 2002), falta de casa ou habitação degradada (viviam choças, tendas, tugúrios ou pátios lisboetas ou ilhas no Porto), egoísmo criminal, etc. Demograficamente essas famílias desfavorecidas contribuíam com o maior número de 'filhos abandonados' ou desamparados (moral e materialmente), não deixando de ser significativo a ilegitimidade em recém-nascidos (pais incógnitos) na época (AULETE, 1925). Ora estas circunstâncias constituíam um passo para a criança fosse um infrator e delinquente e, por isso, as associamos à desviação social, aos fatores exógenos onde ela vivia normalmente, em especial, a rua.

c) Infância desvalida. ('des' confere a situação de não ser válido, do ponto de vista físico, material e cultural). A compreensão da infância desvalida perpassa a conceção da criança e/ou jovem, pois o conceito 'desvalido' (desvaler)remetia para aquela que "não tem valimento para com alguém, que não tem pessoa que o proteja, que lhe valha" (FALCÃO, 1858, p. 683), ou seja, a infância desamparada, abandonada, desgraçada ou miserável. Entendia-se esse termo por desvalimento, que era a falta ou a perda de favor, de proteção, de valimento (FIGUEIREDO, 
1926). Observamos, ainda, que tal significado se assemelha nos dicionários do Séc. XX, por exemplo, no de Caldas Aulete (1925, p. 715) integrava ao de pobre e desgraçado ou seja, desvalido seria a criança desprotegida, desfavorecida pela sorte e deixada ao 'Deus dará' na rua. Em novecentos o Dicionário da Língua Portuguesa (1927) definia desvalido como desprotegido, desamparado, pobre ou desgraçado, e por sua vez, no Dicionário Aurélio (FERREIRA, 1998, p. 352) designa-se aquele "que não possui valor, encontra-se desprotegido, desamparado, desgraçado, miserável".

Mais que um significado, o desvalido legitimava o descaso social e, daí que a infância desvalida e maltratada tomou assento nas denúncias médico-pedagógicas e jurídicas nas classes desfavorecidas (CONSTÂNCIO, 1844). Ora bem, essa infância correspondeu inicialmente à criança exposta/enjeitada, associada à orfandade e pobreza, no séc. XIX (AULETE, 1881, p. 3598), passando, depois a referir-se à abandonada, à pobre e mendiga, isto é, aquela que se encontrava em situação de marginalidade transitória, necessitada de medidas de assistência e educação e de inserção social pelo trabalho. Para esta infância criou-se os asilos, que a par dos destinados à mendicidade foi uma das principais instituições de beneficência pública em Portugal. Os asilos constituíram-se, em 1834, pela Associação das Casas de Asilo da Infância Desvalida, o primeiro deles em Lisboa, depois Porto, Coimbra, Leiria e Aveiro e outras cidades. Estas instituições de enclausuramento, provenientes de iniciativa e/ou estímulo público, mobilizaram participação de filantropos na assistência à infância, sob o duplo signo da caridade e interesse de manutenção da ordem social vigente. Houve uma época que nos asilos, por falta de condições de higiene, os internados eram acometidos de viroses e doenças, aumentando as taxas de enfermidade e mortalidade infantil. Esta preocupação médico-higienista trouxe a debate a defesa ou não dos asilos e sua eficácia na prevenção, contudo o caráter disciplinador dessas instituições converteu-se na tónica do discurso jurídico-social à situação da criança moral e materialmente abandonada (=desvalida), que representava uma ameaça social.

d) Infância delinquente. A delinquência consistia no séc. XIX Dicionário Caldas Aulete (1881, p. 1321) num "estado, caráter ou qualidade de delinquente", já que delinquente significava os menores que "delinquem [...] pessoa que cometeu um delito, criminoso", culpado ou infrator. Este termo não se confundia com o desvalido, pois a infância desvalida era a pobre, desamparada, desprotegida, infeliz, miserável, desgraçada (AULETE, 1881, p. 1474). Ora os menores 
delinquentes dos 14 aos 16 ou 18 anos, salvo exceções, praticavam delitos, transgressões e/ou infrações penais, também, designados por transviados, desajustados, autores ou cúmplices de factos qualificados por crimes ou contravenções. Todas estas questões passaram a ser reguladas pela LPI (PORTUGAL, 1911) e reajustados em alguns dicionários (AULETE, 1925; FIGUEIREDO, 1926).

e) Infância marginalizada. A marginalização abrangia uma multiplicidade de designações associadas à situação da infância, à margem da sociedade do seu tempo, em que muitos desses vocábulos que com ele se relacionam são tidos por sinónimos, mas que expressam significados diferentes, segundo a época histórica. São exemplos as nomenclaturas de crianças: pobres, expostas, mendigas, abandonadas, desamparadas, desvalidas, vadias, delinquentes ou infratoras. O termo marginalizado nos dicionários de oitocentos não existe, apenas o termo marginal, que manteve o mesmo significado etimológico (AULETE, 1881; CONSTÂNCIO, 1844; FALCÃO, 1858). Em novecentos F. Torrinha (1931, p. 869) atribui-lhe o significado: "relativo ou pertencente à margem (do rio, do livro)" que mais tarde veio a ser de 'excluído' da sociedade (AULETE, 1958).

Por conseguinte, sendo a criança e a infância uma construção social e/ou cultural, resultado de práticas e representações (CHARTIER, 2002), difundidas num determinado tempo e espaço histórico, eram na realidade categorias estabelecidas pelas ciências (médicas, pedagógicas, jurídicas e psicológicas). Ora categorias e representação implicam conceções de apropriação. Esta apropriação, segundo Chartier (2002, p. 184), visava a elaboração de uma "história social dos usos e das interpretações", relacionadas às suas determinações fundamentais e inscritos nas práticas específicas que as constroem. Ou seja, a apropriação inseria-se na génese da historia cultural dos saberes médico-pedagógicos, jurídicos e criminológicos, higienistas (eugenistas) e psicológicos, no tempo histórico e assumido pelas autoridades públicas, com a implementação do modelo de assistir, educar, disciplinar e regenerar a infância (desvalida) e, em especial, na resolução dos problemas do menor abandonado e delinquente (CUNNINGHAM, 1998). Mediante essas denominações verificámos, através dos discursos político-ideológicos, científicos e das colunas jornalísticos, a preponderância do modelo assistencial e médicopedagógico, de caráter filantrópico, na prestação de serviços e na sua organização racional (PINTO, 1999). 
Na verdade, todas essas infâncias, que designamos por 'Outra Infância', foram motivo de políticas sociais, cujas respostas foram de teor assistencial/educativo e repressivas, associadas aos modelos práticos de correção e regeneração. Essa 'Outra Infância' teve reformas sociais e assistenciais, com destaque para o papel das Misericórdias, com os objetivos de a acolher, educar e reinserir socialmente. Tratava-se de uma estratégia higienista e eugenista de regeneração moral da Nação que, aos poucos, acentuou o caráter preventivo e a ação social e pedagógica da reeducação da infância (ARCHARD, 1993).

De facto, a criança passou a ser o centro de estudo de várias ciências (pedologia/psicologia, direito, psiquiatria e criminologia, medicina e pediatria, puericultura, etc.). Por influxo da corrente positivista, a partir oitocentos, criaram-se movimentos, grupos, associações ou sociedades preocupadas pela 'salvação da criança' e pelo seu estatuto. Ora essas ações materializavam-se em dispositivos de prevenção, serviços de ajuda e proibições (mendicidade, trabalho infantil) e, ainda, a fundação de instituições (asilos, colégios, casas de correção, recolhimentos, escolas agrícolas, institutos médico-pedagógicos, escolas de reforma, reformatórios, etc.). Em novecentos a criança passou a ser objeto quantificável e de investigação, que gradualmente se converteu em conteúdos culturais, educativos e morais, no tempo e espaço próprio (familiar, escolar, social), de forma controlada, disciplinada e regulada.

\section{Argumento: a ('outra') infância e a legislação de proteção}

Apenas no séc. XIX se ratificou uma conceção humanista sobre a criança e a infância, o menino (meninice) e a adolescência, no sendo este último termo muito comum nos dicionários daquele centúrio. Os documentos jurídico-legais ou jurídico-sociais promulgados nas primeiras décadas do Séc. XX e, em especial, na 1. ${ }^{\circ}$ República (1910-26), possibilitam-nos compreender como se estruturavam, de forma sistemática e articulada os serviços (jurisdicionais de menores, de assistência social e educação), as instituições de internamento (públicas, privadas) e a aplicação dos modelos de tratamento (médico-pedagógico e psicopedagógico) a essa infância detida judicialmente e tutelada pelo Estado (OLIVEIRA, 1929). No cenário internacional também se articulava os discursos sobre a criança às políticas sociais e de proteção da infância. O desígnio de cientificismo de finais do Séc. XIX e inícios do XX desencadeou muitos estudos sobre a criança, especialmente, a criança desvalida, abandonada, delinquente ou criminosa, de tal modo que houve vários certames e congressos internacionais de proteção e assistência. 
Por outro lado, o termo 'menor' passou a ser utilizado na literatura como sinónimo de criança, adolescente e jovem, delimitando a responsabilidade civil e penal a partir do Séc. XIX. Se a criança até aos 14 anos se referia a uma etapa de vida humana, o menor qualificava a condição (em perigo de ou em risco), em que se encontrava essa criança/jovem. Contudo, desde finais desse século, os juristas passam a utilizar aquele termo para designar as crianças ou infância e adolescentes como viciosos, moral e materialmente abandonados, em marginalidade e/ou em delinquência que, sem estarem sob a autoridade dos pais ou tutores, dependiam do Juiz de Órfãos ou curador de menores e entregues às instituições de assistência e educação (regeneração) e, depois, com a publicação da LPI (PORTUGAL, 1911), sob tutela das Tutorias de Infância (permanecendo um período temporário nos Refúgios anexos às Tutorias Centrais e/ou internados em instituições tutelares) e ajudada pela Federação Nacional dos Amigos e Defensores das Crianças (MARTINS, 2012; OLIVEIRA, 1929). O menor infrator era um ocioso que se queria regenerado, pela correção e disciplina do trabalho (agrícola, ofícios artesanais). Os próprios discursos jurídico-legais e/ou jurídico-sociais tinham as suas representações sobre o menor, passando a ser uma categoria jurídica, já integrada nos códigos penais de oitocentos e, depois no direito tutelar de menores.

Historicamente foram surgindo dispositivos de controlo social, implementando tecnologias preventivas, aplicáveis à saúde mental (loucura) e ao crime, muito adequada às estratégias preconizadas de defesa social, que advogava a prevenção da delinquência e criminalidade, sobretudo norteada desde a educação das crianças: essa foi a razão por que as entidades maçónicas se perfilavam na institucionalização de estruturas vocacionadas para a educação, o que assumiu uma relevância na alfabetização do povo e da escolarização das crianças. Este novo cenário de gerir as desordens e impondo coordenadas de ação de normalização, com recurso às vias profiláticas, privilegiaram a adoção de mecanismos hábeis à intervenção ortopédica(a biopolítica), (terminologia de Foucault) junto das crianças em perigo moral, as desamparadas e/ou abandonadas e delinquentes (MARTINS, 2015). Na verdade a política social destinada à infância e às mães/família significou, para os republicanos, um investimento útil, a par de outros como a laicização, a promoção dos interesses dos menores (direito tutelar) pela educação e pela proteção moral e jurídica.

A LPI (PORTUGAL, 1911) constituiu a referência da proteção, da assistência e (re)educação à infância, sendo Portugal um dos países europeus pioneiros. Esse diploma continha 
um conjunto de enunciados e propósitos, já iniciados no Decreto 01 de janeiro de 1911, que visava as condições de pobreza e exclusão social que existia no país. A preocupação pela infância, em geral, e pela 'Outra Infância' mereceu ancoragem de estudos e discursos científicos no período republicano, desde a medicina (social, higienista, psiquiatria), a pedologia ou paidologia, o direito e criminologia, a psicologia e a sociologia, que aprofundaram as suas experimentações e/ou observações. Já nos finais dos oitocentos, na Europa, se tinha gerado uma articulação entre a medicina mental, o direito penal e a pedagogia (correcional), numa perspetiva profilática. Igualmente, o tradicional positivismo, condensado nas componentes sociais, impregnou o ambiente republicano, com uma tendência socializante/socializadora e acompanhada pela influência maçónica, que perpassava esses propósitos sociais. A preocupação dos interesses das crianças constituiu o ideário republicano, bem evidente pelo número de instituições e organizações criadas na prática - lactários, asilos para a infância desvalida, escolas oficinas e municipais, internatos, escolas de reforma e depois reformatórios, a partir de 1919 até 1962 (MARTINS, 2015).

Aquele diploma (PORTUGAL, 1911) expressava, no seu Preâmbulo, o seu objetivo: "visa à educação, à purificação, ao aproveitamento da criança", procurando a recuperação da infância, já que “[...] a assistência, a proteção à infância não passou, até esta data, das aspirações melancólicas dos legisladores do futuro!”. Proteger e regenerar (moralmente) eram as palavras de ordem dessa ideia de 'Salvar a Raça', terminologia utilizada pelo Pe António d' Oliveira (MARTINS, 2012), ao reconhecer-se a necessidade da prevenção - da criança. As questões da imputabilidade do menor merece uma atenção redobrada, com a aplicação do âmbito curativo, sendo necessário alterar a idade de imputabilidade, interdizendo o julgamento a menores até 16 anos, os quais não devem ser considerados criminosos vulgares sendo indispensável exercer a ação, tal como diz no Preâmbulo, com "carácter de quem previne, tutelando, guiando, educando, do que de quem castiga atos resultantes da irreflexão da idade, e principalmente do meio, da atmosfera saturada de venenos que esses pequenos irresponsáveis respiram" (PORTUGAL, 1911). Esta discursividade legislativa tutelar naquele diploma definiu, numa perspetiva preventiva, as diretrizes da proteção, do preparar e retemperar os caracteres dos menores e procurar-lhe e fomentar energias úteis (OLIVEIRA, 1929). Assim, o conceito delinquência modificou-se para um sentido subjetivo, mais amplo, ao integrar os pré-delinquentes: vadios, ociosos, libertinos, com tendências viciosas, etc. De facto, o diploma consignava o combate 
contra as más influências do meio envolvente (familiar, social, comunitário, das más companhias, etc.) à criança ou infância.

$\mathrm{Na}$ verdade, o direito tutelar expresso na LPI (PORTUGAL, 1911) estabelecia várias categorias jurídicas (art. 10), incumbindo as tutorias centrais e comarcãs julgar as causas delitivas dos menores em perigo moral (esta designação foi clarificada no Dec. $\mathrm{N}^{\mathrm{o}} 10.767$, de 15 de maio de 1925) (PORTUGAL, 1925), desamparados e delinquentes. Para estas 3 categorias a LPI (PORTUGAL, 1911) prescrevia medidas desde a guarda, vigilância, colocação (definitiva), tratamento (re)educativo ou tutelar, associando a Federação de Proteção à Infância, patronato e assistência pública à tutela dos menores a elas entregues. Assim, neste normativo jurídico os menores eram classificados de 'em perigo moral' (art. 26) integrava: os sem domicílio e sem meios de subsistência, por serem órfãos, ou de pais desconhecidos ou sem tutor; os abandonados recolhidos pelas instituições da Federação Nacional dos Amigos e Defensores das Crianças ou de assistência que os acolhia e educava (art. 28 e 29); os menores pobres com menos de 12 anos sob tutela do Estado, exigindo-se inquérito social aos pias/família do menor e se possuía doenças, podendo interditar-lhes a inibição do poder paternal e serem acolhidos em instituições de assistência (art. 39); os maltratados pela família/pais, a quem lhes era retirado o poder paternal/tutor (processo de inibição) (art. 41 a 57) (MARTINS, 2015, p. 102-108).

Em relação à categoria de 'desamparados', aquele diploma - LPI (PORTUGAL, 1911) integrava os menores ociosos, vadios, mendigos ou libertinos, significava juridicamente aquele menor que isoladamente ou em companhia de outros considerados "ociosos, vadios, mendigos, alcoólicos, gatunos, rufiões, desordeiros, toleradas ou outros entes imorais ou criminosos, vive em estado habitual de ociosidade, vadiagem, mendicidade ou libertinagem" (art. 58). Designavase por menor libertino aquele que vivia da prostituição de outrem, realiza atos obscenos, frequentador de sítios imorais de 'toleradas', tabernas, prostíbulos, espetáculos pornográficos, casas de jogo proibido, etc., sendo, pois, igualado ao desamparado (art. 59). A categoria 'delinquente' na LPI (PORTUGAL, 1911) englobava os menores contraventores ou criminosos, 'indisciplinados' e 'anormais patológicos'. O diploma considerava delinquente o menor julgado por contravenção, infrações, encobridor/cúmplice de crimes ou punidos por comportamentos (antissociais) regulados pela lei penal (art. 62). Os indisciplinados eram os menores incorrigíveis (art. 69) dos estabelecimentos de assistência e educação que pelos seus comportamentos e atitudes requeriam um modelo de tratamento médico-pedagógico de internato mais rigoroso nas 
escolas de reforma/colónias agrícolas correcionais (art. 70 e 122). Os menores considerados 'anormais patológicos' (art. 73) eram os que apresentavam: deficiências (doença mental ou anormalidades intelectuais), fraqueza do espírito, epilepsia histeria ou instabilidade mental) e, ainda se estivessem em situação de abandono, pobreza ou maltrato, desamparo ou delinquência. Além disso, as Tutorias de Infância remetiam esses menores a internamento e cuidados específicos nos Institutos Médico-Pedagógicos de Aurélio da Costa Ferreira (sexo masculino) e da Condessa Rilvas (sexo feminino) (MARTINS, 2015, p. 107-114) .

Convém destacar, neste ponto da infância detida pelas tutorias centrais e comarcãs, a análise e classificação feita pelo primeiro inspetor-geral dos serviços jurisdicionais de menores na $1^{\text {a }}$ República, o Pe. António d'Oliveira (1923), sobre esses menores, com denominações diferenciadas, consoante as suas características intelectuais, morais, físicas e comportamentais, as quais foram relevantes para definir as estratégias de correção e/ou reeducação em contextos nos estabelecimentos específicos (escolas de reforma, reformatórios, colónias agrícolas). Aquele mentor da LPI referia-se às suas observações de menores na Escola de Reforma de Lisboa: extraviados, retardados, débeis, campónios, broncos, súcios e os magalas (MARTINS, 2012). Extraviados incluía os menores que eram "primitivamente bons e que, em certa altura da vida, se tornaram maus e perigosos, já pelo contacto com certas companhias” (D’OLIVEIRA, 1923, p. 218). O termo retardado, que aparece também na classificação usada em termos médicopedagógicos e/ou da pedologia da época, correspondia aquelas crianças que possuíam algum 'emperro' no âmbito do aparelho intelectual, por falta de uso, de tal modo que as designações débeis (influência de Itard e Séguin), eram os menores cujo " aparelho intelectivo se apresenta fraco e doente" (D’OLIVEIRA, 1923, p. 238). O bronco designava os que tinham "o cérebro entorpecido por bebidas ou alimentação, avariado pelo abuso de determinados vícios." (D’OLIVEIRA, 1923, p. 241). Por fim, os campónios, os magalas e os súcios diziam respeito aos menores que "se movem mais pelo instinto, pela massa instintiva e pelo hábito do que pela inteligência ou pela consciência, são, na verdade, os que atendem, mas não entendem" (D'OLIVEIRA, 1923, p. 242).

Em definitiva, a norma do direito tutelar de menores, denotava uma cultura de proteção, guarda e vigilância à integridade física, psicológica e à saúde e bem-estar da daquelas categorias de infância mencionadas na LPI de 1911(PORTUGAL, 1911), modificada, parcialmente, pelos decretos de 1925 e 1936, 1938 e 1962. 


\section{Considerações finais}

O estudo assentou nas abordagens da história social da infância e/ou história da educação [social], associadas à compreensão das conceções da criança e infância, proveniente dos significados terminológicos dos dicionários e dos discursos científicos e político-ideológicos da época, os quais subsidiaram metodologicamente a nossa análise. Referimo-nos, também, aquela parcela de infância classificada de 'Outra Infância', que tiveram dispositivos e tratamento diferenciados da infância dita normal, escolarizada.

Enquanto a conceção de criança se referia em termos gerais à dinâmica do desenvolvimento da criança individual para ser adulto, a conceção de 'infância' expressava a construção social da criança, que foi objeto de várias classificações e, integrou um leque de distribuições sociais relacionadas com as diferentes classes sociais, culturais, raça, género, situações de limitações ou deficiências, abandono, de desviação social ou delinquência, na escola, na rua ou comunidade. Lembramos que a infância, somente a partir do Séc. XIX, passou a ser observada como infâncias, devido, por um lado, à sua pluralidade social e, por outro lado, ao terse em conta as suas práticas culturais e modos de vida como configuradoras na vida das crianças em diferentes contextos sócio históricos, familiares e políticos (STEARNS, 2006). Coube à sociedade contemporânea fazer emergir uma conceção de infância, instituída pela modernidade e por várias ciências que dela se ocuparam, principalmente as teorias psicológicas do desenvolvimento, em que a criança passou a considerar-se um 'vir a ser'.

Porém, pela organização social de serviços de assistência social, integrou-se a intencionalidade educativa, presente nas instituições jurídicas (tutorias de infância, tribunais de menores), assistenciais e de educação, que foram substituindo a tradição hospitalar e carcerária por asilos, colégios, casas de correção e colónias agrícolas e, posteriormente, por escolas de reforma e reformatórios, a partir de 1919 até 1962. A partir de meados de oitocentos o desenvolvimento científico (médico, psiquiátrico e pedagógico) consolida as tendências de valorização da infância e juventude, privilegiando as instituições como a escola elementar (creche, jardim de infância), os internatos (asilos, escolas de reforma, reformatórios), os ambulatórios e as consultas às mães gestantes e lactentes (MARTINS, 2015). É bem verdade que essas instituições tiveram inicialmente uma postura paternalista e bondosa, mas foram assumindo 
uma dimensão autoritária perante a população operária, pobre e mais desfavorecida (PINTO, 1999). Os homens da ciência eram os detentores da 'verdade' em muitos períodos dos últimos dois séculos, sendo capazes de efetuar a distribuição social sob controlo, na perspectiva da 'melhoria da raça', do nacionalismo, patriotismo e civismo e valores tradicionais.

De facto, a irrupção da questão social da infância e dos seus novos problemas associadas às famílias das classes populares, entre o séc. XIX e o XX, desencadearam um intenso debate entre os intelectuais, juristas, médicos, elites da política, filantropos, profissionais e (psico) pedagogos, relativo às condições de vida desses setores sociais mais desfavorecidos, vulneráveis e excluídos, a quem se exigia ordem e coesão social. As crianças foram os destinatários desses dispositivos e medidas de proteção, de novas práticas e programas políticos, por parte do Estado, para além de serem convertidas em sujeito dos discursos científicos e, ainda objeto de estratégias de moralização e normalização. Verificámos que há um deslocamento conceptual dos discursos para a criança/infância, centro estratégico do projeto de modernização, seja como futuro cidadão útil, seja como trabalhador. Uma grande parte da infância não frequentava a escola e, outra parte, era considerada precoce ou 'anormal' (incluídas a deficientes funcionais - física ou psíquica) por falta de socialização e normatividade social. Estas infâncias não se submetiam às regras, apresentavam comportamentos antissociais ou eram lançadas em situação de marginalidade, abandono ou delinquência: a 'Outra Infância'. As autoridades judiciais, administrativas e políticas viam no internamento em instituições a forma de "retirar da esfera pública os cidadãos mais jovens, especialmente se apresentavam indicadores potenciais de desviância, de modo a regenerá-los para o bem da sociedade (MARTINS, 2006, p. 93).O temor social que provocava os delitos para à delinquência ou desviação social dos menores fez que o Estado se incumbisse das situações e condições que eles apresentavam socialmente. Essa imagem ou representação social (cultural) sobre a criança e a sua infância, proveniente da Modernidade, com o influxo dos reformadores sociais (políticas sociais, assistenciais e educativas), dos debates políticoiideológicos em cada época, os discursos científicos das ciências que a abordaram, originaram as medidas de proteção, o direito tutelar (menores), que culminou nos direitos da criança.

Na verdade, A História (Social) da Infância é plural, seletiva e complexa, já que o seu sujeito histórico não tem um desenvolvimento unívoco, pois, para além das fontes documentais, não apresentam a infância na sua totalidade, mas sim infâncias heterogéneas, diversas e fragmentadas, que concetualizamos no termo 'Outra Infância'. 


\section{Referências}

ARCHARD, D. Children, rights and childhood. London: Routledge, 1993.

AULETE, Francisco Júlio Caldas. Diccionario contemporaneo da língua portuguesa. Lisboa: Parceria Antônio Maria Pereira, 1881. 4v.

AULETE, Francisco Júlio Caldas. Diccionario contemporaneo da língua portuguesa. 2. ed. Lisboa: Parceria Antônio Maria Pereira, 1925.

AULETE, Francisco Júlio Caldas. Diccionario contemporaneo da língua portuguesa. 4. ed. Rio de Janeiro: Editora S.A., 1958.

BASTOS, José Timóteo da Silva. Diccionário etymológico, prosódico e orthográfico da língua portugueza. 2. ed. Lisboa: Parceria António Maria Pereira, 1913.

BORRAS LLOP, J. M. (dir.) Historia de la infancia en la edad contemporánea 1834-1936. Madrid: Ministerio de Asuntos Sociales, 1996.

CHARTIER, R. El mundo como representación. Barcelona: Gedisa, 2002.

CONSTÂNCIO, Francisco S. Novo diccionário crítico e etymologico da línguaportugueza. Paris: Angelo Francisco Carneiro, 1844.

COSTA, A. Bruto. Exclusões sociais. Lisboa: Gradiva, 1998.

CUNNINGHAM, H. Histories of childhood. American Historical Review, Oxford, Reino Unido, v. 103, n. 4, p. 1195-1208, out. 1998.

D’OLIVEIRA, Antonio. Deixemos os pais e cuidemos dos filhos. Lisboa: Edição Autor, 1923.

DICIONÁRIO DA LÍNGUA PORTUGUESA. Dicionário etimológico e ortográfico. 16. ed. Rio Janeiro: Liv. Francisco Alves; Paris/Lisboa: Livrarias Aillaund e Bertrand, 1918.

DICIONÁRIO DA LÍNGUA PORTUGUESA. Dicionário etimológico, prosódico e ortográfico. 17. ed. Rio Janeiro: Liv. Francisco Alves; Paris/Lisboa: Livrarias Aillaund e Bertrand, 1927.

DICIONÁRIO DA LÍNGUA PORTUGUESA. Lisboa: Texto Editores, 2005.

DONZELOT, J. A polícia das famílias. Rio de Janeiro: Graal, 1977.

FALCÃO, Agostinho de M. Diccionário da língua portugueza. 6. ed. Lisboa: Typographia de António José da Rocha, 1858. v. 1

FERREIRA, Aurélio Buarque de Holanda. Novo Aurélio século XXI: O dicionário da língua portuguesa. 2. ed. Rio de Janeiro: Nova Fronteira, 1998.

FIGUEIREDO, C. Novo dicionário da língua portuguesa. 4. ed. Lisboa: Arthur Brandão, 1926.

FONSECA, José da. Diccionário da língua portugueza. Paris: J. Marques Nogueira, 1874.

HENDRICK, H. Constructions and reconstructions of british childhood: an interpretative survey, 1800 to the present. In: JAMES, A.; PROUT, A. (org.). Constructing and reconstructing childhood:

contemporary issues in the study of childhood. London: The Falmer Press, 1990. p. 35-96.

HEYWOOD, C. Uma história da infância: da idade Média à época contemporânea no Ocidente. Porto Alegre: Artmed, 2004.

HOUAISS, A.; VILLAR, Mauro de Salles. Dicionário Houaiss da língua portuguesa. Lisboa: Círculo de Leitores (2002). 6v. 

do XX).

LOPES, Maria Antónia. Proteção social em Portugal na Idade Moderna: guia de estudo e investigação. Coimbra: Imprensa da Universidade de Coimbra, 2010.

MARTINS, Ernesto C. A infância desprotegida portuguesa na primeira metade do séc. XX. Infância \& Juventude, Portugual, n. 4, p. 93-130, out./dez. 2006.

MARTINS, Ernesto C. Proteção social e (R)Educação de menores: o Padre António d'Oliveira (18671923). Lisboa: Cáritas Portuguesa, 2012.

MARTINS, Ernesto C. Infância marginalizada e delinquente na $1^{a}$ República (1910-1926). De Perdidos a Protegidos... e educados. Lisboa: Palimage/Terra Ocre, 2015.

MICHAELIS. Dicionário da língua portuguesa michaelis. São Paulo: Melhoramentos, 2002.

OLIVEIRA, Augusto de. Proteção moral e jurídica à infância. Lisboa: Typ. do Reformatório Central de Lisboa 'Padre António D’Oliveira', 1929.

PINTO, Maria de Fátima. Os indigentes, entre a assistência e a repressão: a outra Lisboa no $1^{\circ}$ terço do Século. Lisboa: Livros Horizonte, 1999.

PORTUGAL. LPI - Lei de Proteção à Infância, de 27 de maio de 1911 (D.G. nº 137, 14 de junho, 1911). Portugal: Imprensa Nacional/Casa da Moeda, 1911.

PORTUGAL. D. G. n 10.767, de 15 de maio de 1925 (alteração à LPI de 1911). Portugal: Imprensa Nacional/Casa da Moeda, 1925.

RELVAS, E. Esmola e degredo: mendigos e vadios em Lisboa (1835-1910). Lisboa: Livros Horizonte, 2002.

STEARNS, P. N. A infância. São Paulo: Contexto, 2006.

TORRINHA, Francisco. Moderno dicionário da língua portuguesa para os estudantes e para o povo: ortográfico, prosódico e morfológico. Porto: Livraria Simões Lopes de Domingos Barreira, 1931. 